\title{
Low Neonatal Mortality and High Incidence of Infectious Diseases in a Vietnamese Province Hospital
}

\author{
Binh T. T. Ho, ${ }^{1}$ Alexandra Y. Kruse, ${ }^{2}$ Hue T. H. Le, ${ }^{3}$ \\ Phuong N. Cam, ${ }^{1}$ and Freddy K. Pedersen ${ }^{2}$ \\ ${ }^{1}$ Neonatal Intensive Care Unit, Children's Hospital 1, Ho Chi Minh City, Vietnam \\ ${ }^{2}$ Paediatric and Adolescence Clinic, Juliane Marie Centre, Rigshospitalet, Copenhagen, Denmark \\ ${ }^{3}$ Paediatric Intensive Care Unit, Dong Thap General Hospital, Dong Thap Province, Vietnam \\ Correspondence should be addressed to Binh T. T. Ho; httbinh80@gmail.com
}

Received 2 October 2015; Revised 11 April 2016; Accepted 10 May 2016

Academic Editor: Kasonde Mwinga

Copyright ( 2016 Binh T. T. Ho et al. This is an open access article distributed under the Creative Commons Attribution License, which permits unrestricted use, distribution, and reproduction in any medium, provided the original work is properly cited.

\begin{abstract}
Background. Neonatal deaths constitute the majority of child mortality in Vietnam, but studies are scarce and focus on community settings. Methods. During a 12-month period, all sick neonates admitted to a pediatric department in a province hospital were studied. Potential risk factors of death covering sociodemographic factors, pregnancy history, previous neonatal period, and status on admission were registered. The neonates were followed up until discharge or death or until 28 completed days of age if still hospitalized or until withdrawal of life support. The main outcome was neonatal death. Results. The neonatal mortality was $4.6 \%$ (50/1094). In a multivariate analysis, four associated risk factors of death were extremely low birth weight $(\mathrm{OR}=22.9(2.3-233.4))$, no cry at birth $(\mathrm{OR}=3.5(1.3-9.4))$, and cyanosis $(\mathrm{OR}=3.3(1.2-8.7))$ and shock $(\mathrm{OR}=12.3(2.5-61.5))$ on admission. The major discharge diagnoses were infection, prematurity, congenital malformations, and asphyxia in 88.5\% (936/1058), 21.3\% (225/1058), $5.0 \%$ (53/1058), and 4.6\% (49/1058), respectively. In 36, a discharge diagnosis was not registered. Conclusion. Infection was the main cause of neonatal morbidity. Asphyxia and congenital malformations were diagnosed less frequently. The neonatal mortality was $4.6 \%$. No sociodemographic factors were associated with death. Extreme low birth weight, no cry at birth, and cyanosis or shock at admission were associated with death.
\end{abstract}

\section{Introduction}

Globally, The Millennium Development Goal to reduce child mortality by two-thirds was not achieved yet [1-10]. A recent Lancet paper estimated that about 44 percent of all under-5 deaths occur in the neonatal period [11]. In recent years, neonatal mortality has been a priority on the global health agenda [12]. Studies on neonatal mortality in lowmiddle income countries have increased but are still scarce compared to the magnitude of the problem and most focus on community settings $[3-5,7-10,13,14]$.

In accordance with the international trend, child mortality has decreased significantly in Vietnam within the recent years (22/1000 live births in 2011), but reduction in neonatal mortality is lagging behind with a reported Neonatal Mortality Rate (NMR) of 12/1000 live births [9, 12, 14-22]. Among the reported deaths, the majority $(63-78 \%)$ were related to prematurity, infection, and asphyxia in accordance with the global estimates [1-3, 5, 8, 11, 13, 23]. Most neonatal deaths are expected to occur in a health care facility, since this is where $79 \%$ deliver, and the first days after delivery are known to carry the highest risk of death $[18,19]$. However, peer reviewed studies on neonatal hospital mortality in Vietnam are few $[5,9,14]$.

Aim of the study was to register the number of neonatal deaths, risk factors for death at admission, and causes of neonatal morbidity in a general province hospital.

\section{Materials and Methods}

2.1. Study Setting. Dong Thap Province in South Vietnam on the border to Cambodia has a population of 1.8 million with 31200 live births annually and NMR of 17/1000 live births [24]. The study was conducted in the main hospital 
of the province, Dong Thap Province General Hospital. It is a secondary level hospital with 700 beds, with pediatric and obstetric departments and 6500 deliveries annually [25]. The pediatric department includes a pediatric ward and a pediatric intensive care unit. Neonates are admitted to the pediatric department internally from the obstetric ward and externally from home or referred from lower levels of care in the province [25]. Nasal continuous positive airway pressure, mechanical ventilation, and parenteral nutrition are part of the neonatal care offered in the hospital. Dong Thap Hospital is comparable to the other 12 main provincial hospitals in Southwestern Vietnam with similar socioeconomic conditions and health system structure. The Children's Hospital $1(\mathrm{CH} 1)$ in Ho Chi Minh City provides the most specialized neonatal care in southern Vietnam and is the referral hospital for Dong Thap Hospital and other southern provincial hospitals.

2.2. Study Design and Material. We conducted a prospective study including all sick neonates admitted to the pediatric department of Dong Thap Hospital during a 12-month period from $1 / 4 / 2010$ to $31 / 3 / 2011$. The participants were followed up until discharge (to home or referral to a tertiary level hospital) or death or until 28 completed days if still hospitalized or until withdrawal of life support (WLS). The following groups were excluded: healthy neonates admitted to the obstetric ward with their mothers for standard postnatal care, readmissions during the neonatal period, and lack of family consent to participate in the study.

2.3. Data Collection. At admission, the doctor receiving the neonate completed a structured questionnaire together with the family. Data collected covered sociodemographic factors, pregnancy history, previous neonatal period, and admission status (see Appendices I and II in the Supplementary Material available online at http://dx.doi.org/10.1155/2016/ 2087042). At the end of the follow-up period, data on outcome and ICD-10 diagnoses (one or more diagnoses were assigned) were collected from the hospital computer registry $[18,26]$. Data on death, WLS, and referral in severe condition were also registered in the ward book by the nurses and in a separate list by the head of the pediatric intensive care unit. WLS cases were followed up until 28 completed days of age by telephone. Birth weight was recorded on all deliveries in the hospital during the study period.

2.4. Outcome. The outcome was defined as death or WLS death in the neonatal period ( $\leq 28$ days). WLS was defined as withholding/withdrawing of manual or mechanical ventilation and discharge alive to die at home [27, 28].

Morbidity data were based on the registered discharge diagnosis.

2.5. Data Analysis. Data were entered in Microsoft Access 97 and analyzed in SPSS. Ten percent of the data were entered in duplicate. When compared, the discrepancies between entries were less than $5 \%$.

Associations between risk factors and outcome were analyzed in multivariate logistic regression using backwards

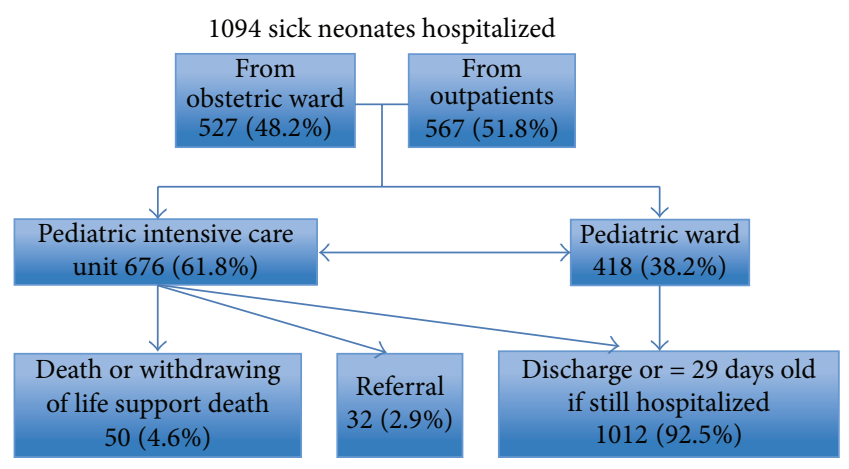

FIGURE 1: Flow chart of the study population.

elimination if $p>0.20$. Unadjusted and adjusted odds ratios $(\mathrm{OR})$ and $95 \%$ confidence intervals (CI) are reported.

2.6. Ethics. The ethical board of the study hospital approved the study. Oral informed consent was sought from the families of the neonates participating. If they rejected or were not present, only basic data were registered from the standard registration. For neonates who had WLS, consent was obligatory prior to follow-up by telephone.

\section{Results}

A total of 1171 sick neonates were admitted to the pediatric department during the 12-month study period. Ten cases rehospitalized in the neonatal period were excluded. Data were missing on 67 cases (5.8\%), leaving 1094 cases available for analysis. No families declined participation. There were no deaths or WLS in the missing group or the excluded group.

As shown in Figure 1, about half (48.2\% or 527/1094) were admitted from obstetrics ward and half from outside. Of the latter $37.7 \%$ or $412 / 1094$ were admitted from home and $13.9 \%$ or 152/1094 were referred from other health care facilities.

During the study period, a total of 6057 live birth deliveries were performed in the hospital, (i.e., approximately a fifth of all live births in Dong Thap Province). Of these $919(15.2 \%)$ were of low birth weight (LBW $<2500 \mathrm{~g})$ and $59(1.0 \%)$ were of very low birth weight (VLBW $<1500 \mathrm{~g})$ (Appendix III). There were 527 (8.7\%) of the babies, delivered in the hospital, that were transferred to pediatric care.

Table 1 shows the characteristics of the study population including male-to-female ratio, gestational age, birth weight, and age of admission in 2 groups from obstetric ward and from outpatients.

The male-to-female ratio in the study was 1.24 . The proportion of premature ( $<37$ weeks) and very premature babies ( $<32$ weeks) was $24.8 \%$ and $6.9 \%$; almost a third (30.4\%) were of LBW and 5.1\% were of VLBW.

Almost a third (29.9\% or 327/1094) were admitted in the first day of life: $48.6 \%$ (256/527) from the obstetric ward and $12.5 \%$ (71/567) from outpatients.

17 cases (1.6\%) were ethnic minorities and $76.5 \%$ or $13 / 17$ of them were admitted from outside. 906 cases of the 1094 $(82.8 \%)$ had attended recommended antenatal care including a minimum of 3 consultations. Approximately half $(47.6 \%$ 
TABLE 1: Characteristics of the study population.

\begin{tabular}{|c|c|c|c|}
\hline & $\begin{array}{c}\text { Obstetric ward (\%) } \\
\qquad N=527\end{array}$ & $\begin{array}{c}\text { Outpatient (\%) } \\
\qquad N=567\end{array}$ & $\begin{array}{l}\text { Total (\%) } \\
N=1094\end{array}$ \\
\hline Male/female & $300 / 227=1.32$ & $306 / 261=1.17$ & $606 / 488=1.24$ \\
\hline \multicolumn{4}{|l|}{ Gestational age } \\
\hline$<28$ weeks & $12(2.3)$ & $4(0.7)$ & $16(1.5)$ \\
\hline 28-31 weeks & $31(5.9)$ & $28(4.9)$ & $59(5.4)$ \\
\hline 32-36 weeks & $124(23.5)$ & $72(12.7)$ & $196(17.9)$ \\
\hline$\geq 37$ weeks & $354(67.2)$ & $417(73.5)$ & $771(70.5)$ \\
\hline \multicolumn{4}{|l|}{ Birth weight } \\
\hline$\leq 1000 \mathrm{~g}$ & $12(2.3)$ & $3(0.5)$ & $15(1.4)$ \\
\hline$<1500 \mathrm{~g}$ & $27(5.1)$ & $14(2.5)$ & $41(3.7)$ \\
\hline$<2500 \mathrm{~g}$ & $158(30.0)$ & $119(21.0)$ & $277(25.3)$ \\
\hline$\geq 2500 \mathrm{~g}$ & $330(62.6)$ & $425(75.0)$ & $755(69.0)$ \\
\hline \multicolumn{4}{|l|}{ Age of admission } \\
\hline Day 1 & $256(48.6)$ & $71(12.5)$ & $327(29.9)$ \\
\hline Day 2-day 7 & $261(49.5)$ & $115(20.3)$ & $376(34.4)$ \\
\hline Day 8-day 28 & $4(0.8)$ & $365(64.4)$ & $369(33.7)$ \\
\hline
\end{tabular}

Data on birth weight, gestational age, and age of admission were missed in 6,52 , and 22 cases, respectively.

TABLe 2: Distribution of diagnoses at discharge in Dong Thap Hospital.

\begin{tabular}{|c|c|c|c|c|}
\hline \multirow[t]{2}{*}{ Discharge diagnosis ${ }^{1}$} & \multicolumn{2}{|c|}{$\begin{array}{l}\text { Dong Thap Hospital } \\
\qquad N=1058^{2}\end{array}$} & \multicolumn{2}{|c|}{$\begin{array}{l}\text { Children's Hospital 1, Ho Chi Minh City } \\
\qquad N=5763[5]\end{array}$} \\
\hline & Cases & $\%$ & Cases & $\%$ \\
\hline Prematurity & 225 & 21.3 & 385 & 6.7 \\
\hline Infection & 936 & 88.5 & 3618 & 62.8 \\
\hline Sepsis/meningitis & 172 & 16.3 & & \\
\hline Skin/umbilical infection & 232 & 21.9 & & \\
\hline Pneumonia & 155 & 14.7 & & \\
\hline Unspecified infection & 377 & 35.6 & & \\
\hline Congenital malformations & 53 & 5.0 & 864 & 15.0 \\
\hline Asphyxia & 49 & 4.6 & 120 & 2.1 \\
\hline Jaundice & 280 & 26.5 & 1060 & 18.4 \\
\hline
\end{tabular}

${ }^{1}$ Each neonate had one or more diagnoses assigned.

${ }^{2} 36$ of 1094 did not have a discharge diagnosis registered.

or 521/1094) had a normal delivery, $25.3 \%$ (277/1094) had a cesarean delivery, and only $0.8 \%$ (9/1094) were delivered at home. $64.6 \%(707 / 1094)$ were breastfed with or without formula milk.

Of the 1094 neonates studied, 654 (59.8\%) were not discharged after birth and 669 (61.2\%) had symptoms for less than 1 day before admission. The most frequent danger symptoms before admission according to parents or caretakers were symptoms related to feeding, breathing, and yellow skin: 11.2\% (123/1094), 17.4\% (190/1094), and 27.1\% (297/1094), respectively. Cyanosis, lethargy/comatose condition, and paleness were detected at admission by the doctor in $10.3 \%$ (113/1094), 5.4\% (59/1094), and 4.1\% (45/1094); symptoms observed by the caretaker like blue skin, movement only on stimulation, difficulty in waking up, or pale skin were less recognized: 5.1\% (56/1094), 0.5\% (6/1094), 0.3\% (3/1094), and $0.2 \%(2 / 1094)$, respectively.

Of the 567 external admissions, 136 (24.0\%) were transported by ambulance from a health care facility and 39 (28.7\%) of 136 deteriorated during transportation.

At admission, 5.9\% (64/1094) of the neonates were in severe condition with severe respiratory failure $(2.0 \%)$, shock (2.4\%), or coma/lethargy (5.5\%).

Table 2 shows the diagnoses assigned at follow-up in 1058 of 1094 (in 36 a discharge diagnosis was not registered) and compares figures for the same diagnosis at Children's Hospital 1, Ho Chi Minh City. Infection was assigned in $88.5 \%$ of the 1058 neonates in the study hospital, and Table 3 shows some 
TABLE 3: Characteristics of neonates with infection.

\begin{tabular}{lccc}
\hline & $\begin{array}{c}\text { Infection group } \\
N=936\end{array}$ & $\begin{array}{c}\text { Total } \\
N=1094\end{array}$ & $\begin{array}{c}\text { Percentage } \\
\%\end{array}$ \\
\hline Admitted from & & & \\
$\quad$ Home & 342 & 412 & 83.0 \\
Other HCF & 146 & 152 & 96.1 \\
Obstetrics ward & 448 & 527 & 85.0 \\
Birth weight & & & \\
$\leq 1000$ g & 12 & 15 & 80.0 \\
1001-1499g & 37 & 41 & 90.2 \\
1500-2499 g & 259 & 277 & 93.5 \\
$\geq 2500$ g & 628 & 755 & 83.2 \\
Age of admission & & & \\
Day 1 & 302 & 327 & 92.4 \\
Day 2-day 7 & 327 & 376 & 87.0 \\
Day 8-day 28 & 307 & 369 & 83.2 \\
\hline${ }^{1}$ HCF: health care facility. & & &
\end{tabular}

TABLE 4: Risk factors of neonatal hospital death.

\begin{tabular}{lcc}
\hline Characteristics & OR adjusted & $p$ value \\
\hline Birth weight & & \\
$\quad \leq 1000 \mathrm{~g}$ & $22.9(2.3-233.4)$ & 0.008 \\
$1001-1499 \mathrm{~g}$ & $4.9(0.9-29.6)$ & 0.087 \\
$1500-2499 \mathrm{~g}$ & $2.8(0.8-10.00)$ & 0.114 \\
No cry at birth & $3.5(1.3-9.4)$ & 0.012 \\
Skin color at admission & & \\
$\quad$ Yellow & $0.1(0.0-1.7)$ & 0.119 \\
$\quad$ Cyanosis & $3.3(1.2-8.7)$ & 0.019 \\
$\quad$ Pale & $2.0(0.5-9.1)$ & 0.364 \\
Shock & $12.3(2.5-61.5)$ & 0.002 \\
\hline
\end{tabular}

characteristics of the neonates with infection. Table 4 shows the multivariate analysis of risk factors of neonatal hospital death.

3.1. Risk Factors of Hospital Death. Neonatal death was registered in 50 neonates, 2 cases of which were WLS and died in the neonatal period, corresponding to a mortality rate of 4.6\% (50/1094). Another 3 WLS cases were alive beyond 28 completed days of age. Further 32 severely ill cases were transferred to tertiary level in Ho Chi Minh City out of which 2 died, 21 cases were alive throughout the neonatal period, and 9 cases were lost to follow-up.

The multivariable logistic regression found extremely low birth weight $(\mathrm{OR}=22.9(2.3-233.4))$, no cry at birth $(\mathrm{OR}=$ $3.5(1.3-9.4))$, and cyanosis $(\mathrm{OR}=3.3(1.2-8.7))$ and shock at admission $(\mathrm{OR}=12.3(2.5-61.5))$ associated with increased risk of death.

\section{Discussion}

This prospective descriptive study included $94.2 \%$ of all admitted neonates to Dong Thap Province hospital during the 12-month study period with no missing cases of death or
WLS. It may therefore be considered representative for the situation in provincial hospitals in at least the southwestern part of Vietnam where socioeconomic conditions, cultural traditions, delivery traditions, referral practices, and levels of care are comparable.

Among the 1094 neonates included, the mortality was $4.6 \%$. This figure does not include 2 cases $(0.2 \%)$ that died during the neonatal period after referral to Children's Hospital 1, Ho Chi Minh City, because these deaths may be influenced by factors other than those of the provincial hospital. Nine referred cases were not available for follow-up, which also adds some uncertainty to the total mortality of the whole cohort. If all cases unavailable for follow-up after referral were assumed dead and those two cases known to be dead after referral were added, the total mortality in the full cohort would be $5.6 \%$ (61/1094). The study only registered events during hospitalization within the neonatal period and did not follow up cases hospitalized beyond 28 days of age, where some deaths could have occurred, as could have been the case in the 3 WLS patients that were alive at 28 days.

To our knowledge, no data of neonatal mortality in hospital in Vietnam with the exception of that from the tertiary Children's Hospital 1 from our group has been published [5]. In a systematic review of the burden of neonatal mortality and morbidity in the ASEAN region published in 2012, among 20 publications included, there were only three studies from Vietnam all focusing on community neonatal mortality [29].

The mortality rate of $4.6 \%$ was low, especially compared to situations where advanced treatment is not available $[1$, $2,16,23,30-32]$. Hospital mortality rates of $13.8 \%$ have been reported from other low and middle income countries $[16,23]$. Many, however, were admitted to hospital due to simple jaundice or mild respiratory problems that could have been admitted to lower level health care facilities. Another likely explanation of the low mortality in this study is the low proportion of VLBW (5.1\%) and asphyxiated (4.6\%) and congenital malformations (5.0\%) in the study population, since all are associated with a high neonatal mortality globally $[1-3,14,23,31]$. The causes of death in this material are being investigated in detail in another study using a death audit procedure.

Babies born very preterm (gestational age $<32$ weeks) and/or with very low birth weight (birth weight $<1500 \mathrm{~g}$ ) had mortality rates of over $50 \%$ in many low-resource settings of Asia or Africa $[8,12,16,33]$ and are at a higher risk for longterm disabilities and impairments $[8,12,16]$. In low-middle income countries, most early neonatal deaths are caused by prematurity $[8,12,16,34]$. Gestational age is an important factor of neonatal mortality, but the relation to hospital death in our study was not statistically significant in the multivariate analysis. However, extremely low birth weight was the strongest risk factor of death (OR adjusted 22.9 (2.3233.4)). "No cry at birth" with OR adjusted $=3.5(1.3-9.4)$ is a symptom that reflects maladaptation of the neonate in the out-of-uterus environment and thus may also be due to severe prematurity, asphyxia, or congenital malformations.

Shock at admission was a strong predictor of death. Indeed, treatment of shock in the neonate was a challenge 
in Dong Thap Hospital, where there were no treatment guidelines and lack of possibilities for monitoring. Severe respiratory failure disappeared in the multivariate analysis, and cyanosis at admission remained one of four final risks factors.

No sociodemographic factors were associated with hospital death. It was an important finding of the study in Dong Thap Hospital and Children's Hospital 1, Ho Chi Minh City, since these factors have been shown to be of importance for infant survival in other low and middle income countries $[1,2,4,5,12,16,21,34,35]$. In our total study, the male-tofemale ratio was 1.24 , in patients from outside was 1.17 , and in those from obstetric ward was 1.32 ; this probably reflects the predominance of males in the community (1.09-1.11) as well as possibly male infant vulnerability $[24,36]$. The ethnic minority rate was $1.6 \%$, higher than the rate in the Dong Thap population (0.6\%) [24], probably reflecting a different health seeking behavior of the ethnic minority group in southern Vietnam. Neither gender nor ethnic minority, however, was related to hospital death. These findings in our study showed no inequity in access to care in treatment and neonatal outcome in Vietnam due to the level of the parent's education, ethnic origin, or the gender of the neonate. We found that young neonates admitted from the obstetric ward were more than those from outside; this probably reflects that women with higher risk of complication of pregnancy or delivery more often are admitted to the province hospital. Besides that, we have not recognized any selection bias for referral. Referral to tertiary hospital is done when highly specialized treatment is needed, for example, neonatal surgery.

The discharge diagnosis of asphyxia was similarly low in Dong Thap Hospital and Children's Hospital 1, Ho Chi Minh City [5], but the limited data available in Vietnam and the ASEAN region probably do not reveal the real burden of birth asphyxia in this region [14]. A study of incidence of hypoxic ischemic encephalopathy in Dong Thap Hospital and a tertiary obstetrics hospital in Ho Chi Minh City, however, is ongoing.

The rate of congenital malformations was 5.0\%, lower than that in Children's Hospital 1, Ho Chi Minh City (15.0\%) [5]. This difference could be explained by the limited capacity of prenatal and postnatal malformation diagnosis and lack of neonatal surgery in Dong Thap Hospital, whereas Children's Hospital 1, Ho Chi Minh City, is a tertiary hospital and a center of neonatal surgery in South Vietnam.

Infection was the main diagnosis assigned to $88.5 \%$ of the patients. Other studies from Vietnam and from other low-middle income countries have also shown high rates of $38.0 \%$ to $62.8 \%[2,5,16,23]$. Unspecified infection was assigned to $35.6 \%$ as there were no specific diagnostic criteria for assigning the diagnosis by the treating physician. It is therefore likely to be based on a clinical impression, which may be incorrect. But even if the cases classified as unspecific infections are deducted, an infection rate of the resulting $52.9 \%$ is high. According to global figures, infections cause $30-50 \%$ of the neonatal mortality burden in low income countries $[8,23]$, and the incidence of late-onset sepsis was higher in Asia than in resource-rich countries [37]. This high figure may reflect insufficient hygienic procedures at home or in the hospital $[23,29]$. The rate of infection was highest in the group transferred from the other health care facilities (96.1\% or $146 / 152)$, followed by those from the obstetrics ward $(85.0 \%, 448 / 527)$ and $83.0 \%$ or $342 / 412$ from home. This suggests that nosocomial infection in hospitals in the region may be a problem. An infection diagnosis is likely to affect antibiotic prescription and thus favor a high prevalence of bacteria resistant to antibiotics [14, 23, 29]. To prevent the growing problem of antibiotic resistance, specification of diagnostic infection criteria will be important. Further it may contribute to improving efforts to identify other relevant diagnoses and hence proper management of the neonatal cases. Health education of mothers and training of hospital staff on proper hygienic measures and infection control are likewise important to reduce the incidence of neonatal infection.

After finalization of the research, the training of medical staffs in basic newborn care was established and maintained. The neonatal infection diagnosis criteria and shock guidelines were updated. The infection control program in the hospital received more interest and the health education program for mothers and family members of sick neonates was realized within the scope of hospital.

\section{Conclusions}

This study of mortality and morbidity among 1094 consecutively admitted sick neonates in a general province hospital in South Vietnam contributes to the limited data on hospital admitted neonates in Vietnam. Infection was the main cause of neonatal morbidity. Asphyxia and congenital malformations were diagnosed less frequently than expected.The neonatal hospital mortality was $4.6 \%$. No sociodemographic factors were associated with neonatal death. The risk factors statistically significantly related to death were extremely low birth weight, no cry at birth, and cyanosis or shock at admission. Introduction of specific diagnostic criteria for infection to reduce improper antibiotic use and the development of antibiotic resistance and health education of mothers and training of hospital staff in hygienic measures and infection control may help reduce neonatal infections. The instruction of updated shock guidelines is crucial.

\section{Competing Interests}

The authors declare that there are no competing interests regarding the publication of this paper.

\section{Authors' Contributions}

All of the authors contributed to the study planning. Binh T. T. Ho and Hue T. H. Le performed the data collection and the data management. Binh T. T. Ho performed the analysis and wrote the first draft of the paper. Binh T. T. Ho, Alexandra Y. Kruse, and Freddy K. Pedersen contributed to the interpretation of the data and the discussion.

\section{Acknowledgments}

Danish Vietnamese Association (DVA) and Danish International Development Agency (DANIDA) supported the study. 


\section{References}

[1] M. Gizaw, M. Molla, and W. Mekonnen, "Trends and risk factors for neonatal mortality in Butajira District, South Central Ethiopia, (1987-2008): a prospective cohort study," BMC Pregnancy and Childbirth, vol. 14, article 64, 2014.

[2] I. K. Bucens, A. Reid, A. C. Barreto, V. Dwivedi, and M. Counahan, "Three years of neonatal morbidity and mortality at the national hospital in Dili, East Timor," Journal of Paediatrics and Child Health, vol. 49, no. 6, pp. 452-457, 2013.

[3] A. Rammohan, K. Iqbal, and N. Awofeso, "Reducing neonatal mortality in India: critical role of access to emergency obstetric care," PLoS ONE, vol. 8, no. 3, Article ID e57244, 2013.

[4] M. Målqvist, D. T. P. Hoa, and S. Thomsen, "Causes and determinants of inequity in maternal and child health in Vietnam," BMC Public Health, vol. 12, article 641, 2012.

[5] A. Y. Kruse, B. T. T. Ho, C. N. Phuong, L. G. Stensballe, G. Greisen, and F. K. Pedersen, "Prematurity, asphyxia and congenital malformations underrepresented among neonates in a tertiary pediatric hospital in Vietnam," BMC Pediatrics, vol.12, article 199, 2012.

[6] United Nations, “The Milenium Development Goals Report 2012," 2012, http://www.un.org/millenniumgoals/pdf/MDG\% 20Report\%202012.pdf.

[7] N. T. Nga, M. Malqvist, L. Eriksson et al., "Perinatal services and outcomes in Quang Ninh province, Vietnam," Acta Paediatrica, vol. 99, no. 10, pp. 1478-1483, 2010.

[8] M. Indah, N. U. Budha, W. Retayasa, and M. Kardana, "Early neonatal mortality rate and the risk factors in Wangaya hospital," Paediatrica Indonesiana, vol. 48, no. 5, pp. 306-311, 2008.

[9] K. Hill and Y. Choi, "Neonatal mortality in the developing world," Demographic Research, vol. 14, article 18, pp. 429-452, 2006.

[10] I. Jehan, H. Harris, S. Salat et al., "Neonatal mortality, risk factors and causes: a prospective population-based cohort study in urban Pakistan," Bulletin of the World Health Organization, vol. 87, no. 2, pp. 130-138, 2009.

[11] L. Liu, S. Oza, D. Hogan et al., "Global, regional, and national causes of child mortality in 2000-13, with projections to inform post-2015 priorities: an updated systematic analysis," The Lancet, vol. 385, no. 9966, pp. 430-440, 2015.

[12] S. M. Dhaded, M. S. Somannavar, S. S. Vernekar et al., "Neonatal mortality and coverage of essential newborn interventions 2010-2013: a prospective, population-based study from lowmiddle income countries," Reproductive Health, vol. 12, supplement 2, p. S6, 2015.

[13] N. T. Nga, D. T. P. Hoa, M. Malqvist, L.-A. Persson, and U. Ewald, "Causes of neonatal death: results from NeoKIP communitybased trial in Quang Ninh province, Vietnam," Acta Paediatrica, vol. 101, no. 4, pp. 368-373, 2012.

[14] H. T. Tran, L. W. Doylec, K. J. Leed, and S. M. Grahamb, "A systematic review of the burden of neonatal mortality and morbidity in the ASEAN Region," WHO South-East Asia Journal of Public Health, vol. 1, no. 3, pp. 239-248, 2012.

[15] V. Govande, A. R. Ballard, M. Koneru, and M. Beeram, “Trends in the neonatal mortality rate in the last decade with respect to demographic factors and health care resources," Proceedings (Baylor University. Medical Center), vol. 28, no. 3, pp. 304-306, 2015.

[16] M. Hoque, S. Haaq, and R. Islam, "Causes of neonatal admissions and deaths at a rural hospital in KwaZulu-Natal, South
Africa," Southern African Journal of Epidemiology and Infection, vol. 26, no. 1, pp. 26-29, 2011.

[17] J. Bryce, C. Boschi-Pinto, K. Shibuya, and R. E. Black, "WHO estimates of the causes of death in children," The Lancet, vol. 365, no. 9465, pp. 1147-1152, 2005.

[18] J. E. Lawn, D. Osrin, A. Adler, and S. Cousens, "Four million neonatal deaths: counting and attribution of cause of death," Paediatric and Perinatal Epidemiology, vol. 22, no. 5, pp. 410416, 2008.

[19] WHO, Child Survival Profile: Viet Nam, WHO, Geneva, Switzerland, 2007.

[20] Group The Young Infants Clinical Signs Study, "Clinical signs that predict severe illness in children under age 2 months: a multicentre study," The Lancet, vol. 371, no. 9607, pp. 135-142, 2008.

[21] D. P. Hoa, N. T. Nga, M. Målqvist, and L. Å. Persson, “Persistent neonatal mortality despite improved under-five survival: a retrospective cohort study in northern Vietnam," Acta Paediatrica, vol. 97, no. 2, pp. 166-170, 2008.

[22] WHO, World Health Statistics 2013, World Health Organization, 2013.

[23] N. Aijaz, N. Huda, and S. Kausar, "Disease burden of NICU, at a tertiary care hospital, Karachi," Journal of the Dow University of Health. Sciences Karachi, vol. 6, no. 1, pp. 32-35, 2012.

[24] Reproductive Health Care Center of Dong Thap Province, Annual Report of Reproductive Health Care Center of Dong Thap Province, 2012.

[25] Annual Report of Dong Thap General Hospital, 2010.

[26] J. B. Ford, C. L. Roberts, C. S. Algert, J. R. Bowen, B. Bajuk, and D. J. Henderson-Smart, "Using hospital discharge data for determining neonatal morbidity and mortality: a validation study," BMC Health Services Research, vol. 7, article 188, 2007.

[27] J. M. Luce, "Withholding and withdrawal of life support: ethical, legal, and clinical aspects," New Horizons: Science and Practice of Acute Medicine, vol. 5, no. 1, pp. 30-37, 1997.

[28] J. Hellmann, R. Knighton, S. K. Lee et al., "Neonatal deaths: prospective exploration of the causes and process of end-of-life decisions," Archives of Disease in Childhood, vol. 101, no. 2, pp. F102-F107, 2016.

[29] H. T. Tran, L. W. Doyle, K. J. Lee, N. M. Dang, and S. M. Graham, "A high burden of late-onset sepsis among newborns admitted to the largest neonatal unit in central Vietnam," Journal of Perinatology, vol. 35, no. 10, pp. 846-851, 2015.

[30] S. W. Sharon, C. R. Le Marsney, S. Hossain, R. Haslam, and K. Lui, "Report of the Australian and New Zealand neonatal network 2013," 2015.

[31] K. Aggarwal, R. Gupta, S. Sharma, R. Sehgal, and M. Roy, "Mortality in newborns referred to tertiary hospital: an introspection," Journal of Family Medicine and Primary Care, vol. 4, no. 3, pp. 435-438, 2015.

[32] T. Seyal, F. Husnain, and A. Anwar, "Audit of neonatal morbidity and mortality at Neonatal Unit of Sir Gangaram Hospital Lahore," Annals of King Edward Medical University, vol. 17, no. 1, pp. 9-13, 2011.

[33] A. LeFevre, S. D. Shillcutt, S. K. Saha et al., "Cost-effectiveness of skin-barrier-enhancing emollients among preterm infants in Bangladesh," Bulletin of the World Health Organization, vol. 88, no. 2, pp. 104-112, 2010.

[34] N. T. N. Ngoc, M. Merialdi, H. Abdel-Aleem et al., "Causes of stillbirths and early neonatal deaths: data from 7993 pregnancies in six developing countries," Bulletin of the World Health Organization, vol. 84, no. 9, pp. 699-705, 2006. 
[35] E. M. Brinda, A. P. Rajkumar, and U. Enemark, "Association between gender inequality index and child mortality rates: a cross-national study of 138 countries," BMC Public Health, vol. 15, no. 1, article 97, 2015.

[36] B. Teerawichitchainan and J. F. Phillips, "Ethnic differentials in parental health seeking for childhood illness in Vietnam," Social Science \& Medicine, vol. 66, no. 5, pp. 1118-1130, 2008.

[37] R. Tiskumara, S. H. Fakharee, C. Q. Liu et al., "Neonatal infections in Asia," Archives of Disease in Childhood: Fetal and Neonatal Edition, vol. 94, no. 2, pp. F144-F148, 2009. 


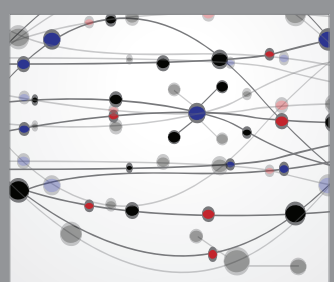

The Scientific World Journal
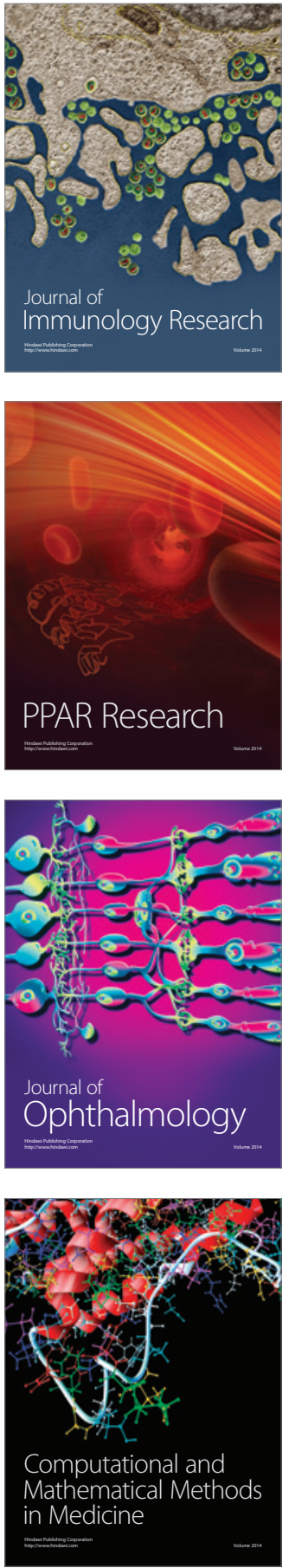

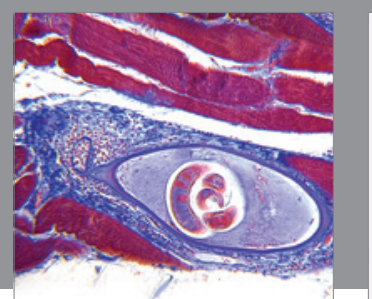

Gastroenterology Research and Practice

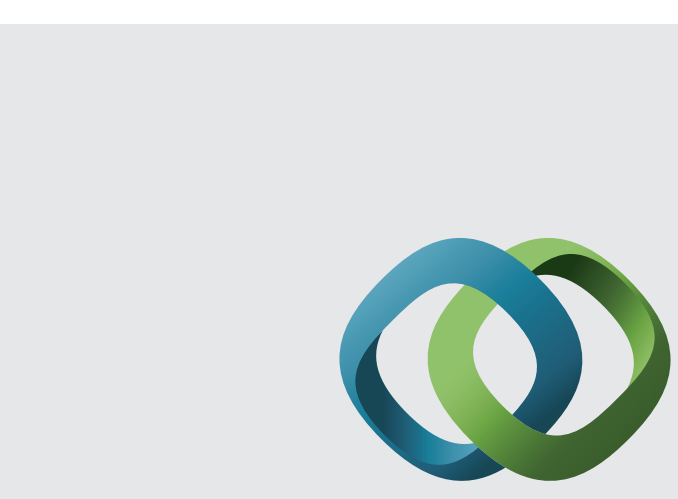

\section{Hindawi}

Submit your manuscripts at

http://www.hindawi.com
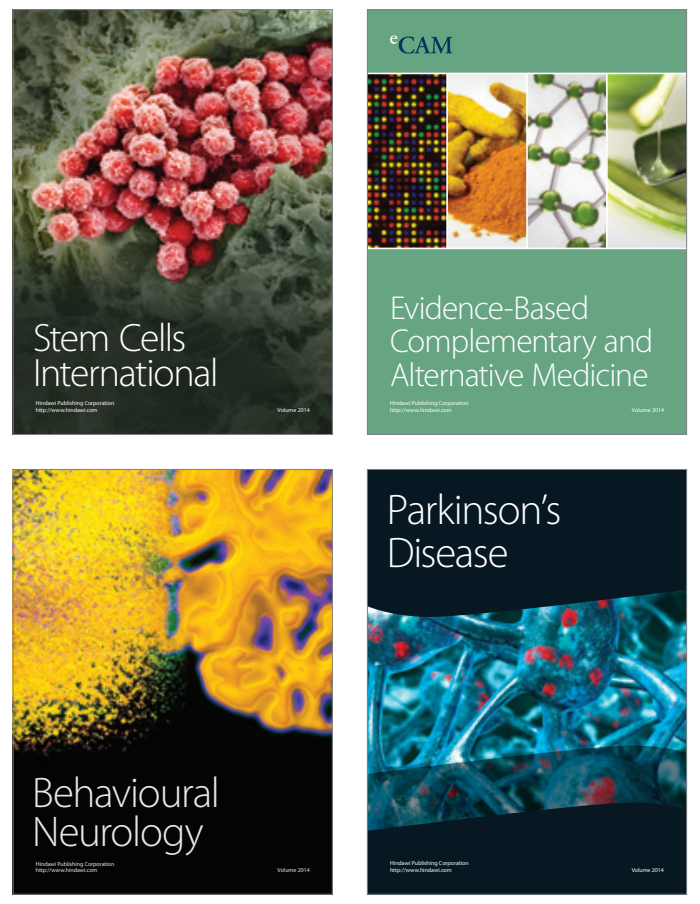
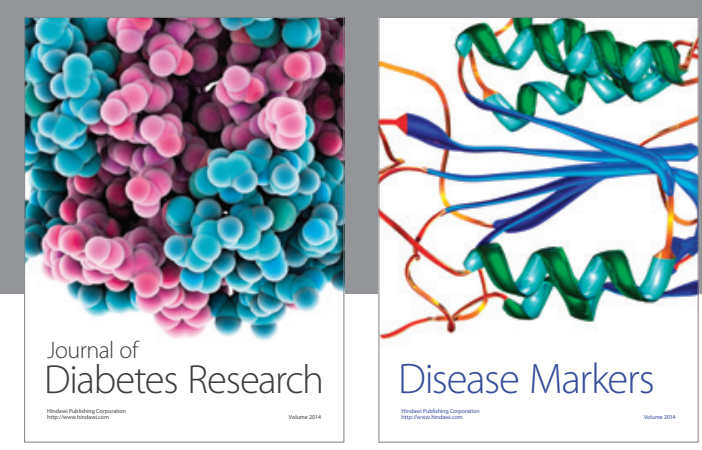

Disease Markers
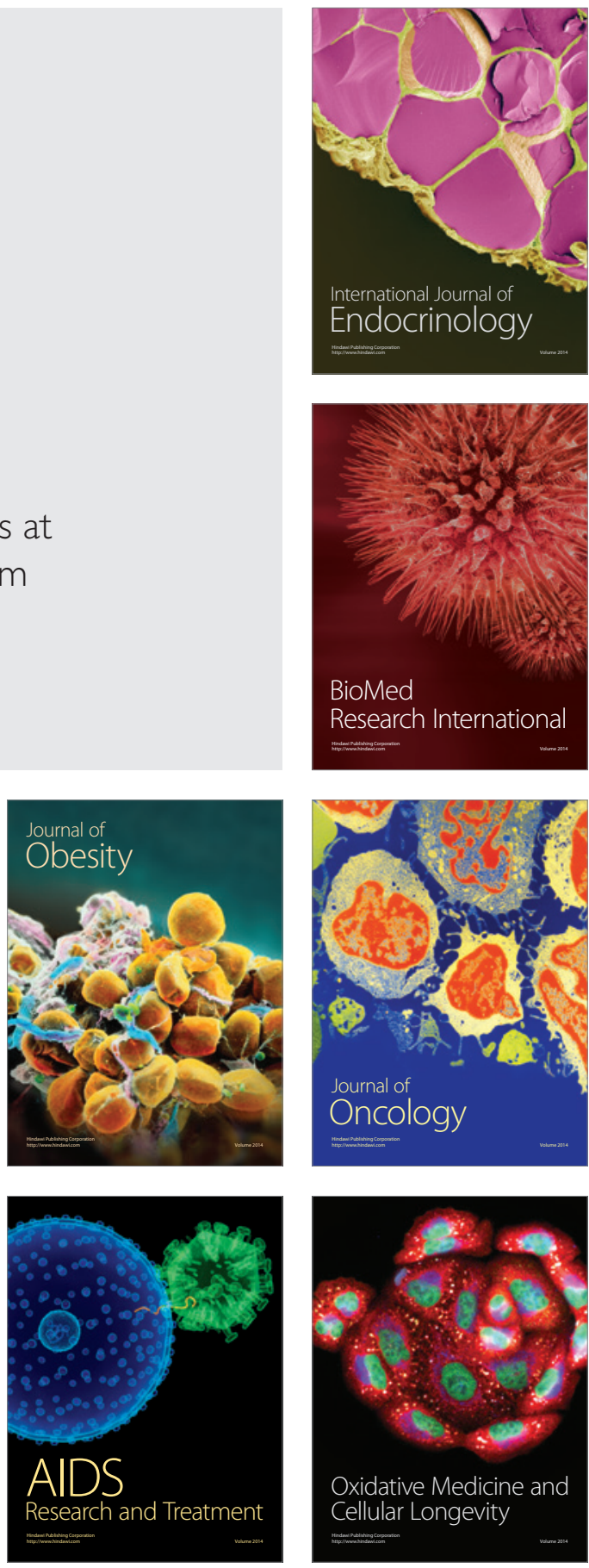